\title{
ASSOCIATION BETWEEN PHYSICAL FUNCTIONING WITH COGNITION AMONG COMMUNITY-DWELLING OLDER ADULTS: A CROSS-SECTIONAL STUDY
}

\author{
Associação entre função física e cognição em \\ idosos da comunidade: estudo transversal
}

\author{
Juliana Fonseca Nogueira Alves ${ }^{\mathrm{a}}$, Bruno Remígio Cavalcante ${ }^{\mathrm{b}} \bullet$,

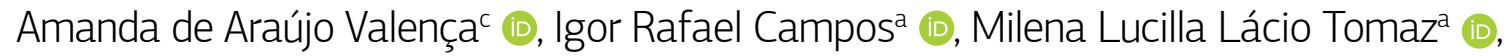 \\ Rodrigo Cappato de Araújob $\oplus^{\mathfrak{C}, \text { Mariana Ferreira de Souza }}{ }^{\mathrm{a}}$
}

OBJECTIVE: Declines in physical and cognitive functioning often co-exist through aging. Gait-related parameters have been related to cognitive function, although it is unclear whether other measures of physical functioning are similarly related to cognition. Here, we analyzed the relationship between physical functioning with cognition in older adults. METHODS: In total, baseline data of 116 dementia-free older adults recruited from two separated clinical trials (RCT) were included (M age = 69 years, SD = 6; 71\% women). We quantified cognitive functioning using the Montreal Cognitive Assessment (MoCA) and executive functioning tasks (Digit Span Forward minus Backward and verbal fluency - FAS and animal naming). Physical function measures included gait speed, Short-physical Performance Battery (SPPB), five-times Sit-to-Stand Test, the Timed Up and Go (TUG) test, the Six-minute Walk Test (6MWT), and lower extremity muscle strength. We used multiple linear regression analyses to explore the association between cognitive measures and each measure of physical functioning, adjusting for age, sex, education, and RCT. Regression coeficients (b), standard error (SE) and 95\% confidence intervals (CI) were used to summarize main results. RESULTS: We observed a positive association between muscle strength and the MoCA ( $b=0.84, \mathrm{SE}=0.40,95 \% \mathrm{Cl} 0.05-1.64$ ) after controlling for covariates. Significant associations were also found between the five-times-sit-to-stand test $(b=-0.63$, $\mathrm{SE}=0.26,95 \% \mathrm{Cl}-1.15--0.12)$, TUG $(b=-1.13, \mathrm{SE}=0.57,95 \% \mathrm{Cl}-2.26--0.01), 6 \mathrm{MWT}(\mathrm{b}=0.04, \mathrm{SE}=0.02,95 \% \mathrm{Cl} 0.01-0.07)$, and lower extremity muscle strength $(b=1.92, \mathrm{SE}=0.93,95 \% \mathrm{Cl} 0.09-3.77)$ with the FAS verbal fluency test, and between the TUG ( $b=-0.62, \mathrm{SE}=0.24,95 \% \mathrm{Cl}-1.11--0.14)$ with animal naming. CONCLUSION: In community-dwelling older adults, higher levels of muscle strength, dynamic balance and cardiorespiratory fitness were positively related with global cognition and executive control measures.

KEYWORDS: aging; cognition; cognitive impairment; functional performance.

aDepartment of Physical Education, Clinical Exercise Lab (LABEC), Universidade Federal do Vale do São Francisco - Petrolina (PE), Brazil.

${ }^{b}$ Graduate Program in Rehabilitation and Functional Performance, Universidade de Pernambuco - Petrolina (PE), Brazil.

'Department of Physical Therapy, Laboratório de Pesquisa em Saúde e Desempenho Funcional, Universidade de Pernambuco - Petrolina (PE), Brazil.

Correspondence data

Mariana Ferreira de Souza - Universidade Federal do Vale do São Francisco -Avenida José de Sá Maniçoba, s/n - Centro - CEP: $56304-917$ - Petrolina (PE), Brazil. E-mail: mariana.ferreirasouza@univasf.edu.br @labec_univasf

Received on: 01/18/2021. Accepted on: 04/08/2021

How to cite this article: Alves JFN, Cavalcante BR, Valença AA, Campos IR, Tomaz MLL, Araújo RC, et al. Association between physical functioning with cognition among community-dwelling older adults: a cross-sectional study. Geriatr Gerontol Aging. 2021;15:e0210025. https://doi.org/10.53886/ gga.e0210025

https://doi.org/10.53886/gga.e0210025 
OBJETIVO: Declínios na função física e cognitiva frequentemente coexistem no envelhecimento. Parâmetros da marcha têm sido relacionados à função cognitiva, porém é incerto o quanto outras medidas da função física são, similarmente, associadas à cognição. Nós analisamos a relação entre função física e a cognição em idosos. MÉTODOS: No total, 116 participantes foram incluídos no estudo ( $M$ idade = 69 anos, DP = 6; 71\% mulheres). Quantificou-se a função cognitiva usando o Montreal Cognitive Assessment (MoCA) e testes de função executiva (Digit Span Forward - Backward e testes de fluência verbal). As medidas de função física incluíram velocidade de marcha, Short-physical Performance Battery (SPPB), teste de sentar e levantar, Timed Up and Go (TUG), teste de caminhada de seis minutos (6MWT), e força muscular de membros inferiores. As análises de regressão linear múltipla foram utilizadas para explorar a associação entre medidas cognitivas e cada medida da função física, controlando pela idade, sexo, escolaridade e estudo. RESULTADOS: Nós observamos uma associação positiva entre força muscular e o MoCA (b = 0.84 , SE $=0.40,95 \% \mathrm{Cl} 0.05-1.64)$ após controle pelas covariáveis. Associações significativas foram encontradas entre o teste de sentar e levantar ( $b=-0, .63, \mathrm{SE}=0, .26$, IC 95\%Cl -1,.15--0,.12), TUG (b = -1,.13, SE = 0,.57, IC 95\%Cl -2,.26--0,.01), 6MWT ( $b=0, .04, \mathrm{SE}=0, .02$, IC 95\%Cl 0,.01-0,.07), e força muscular de membros inferiores ( $b=1, .92, \mathrm{SE}=0, .93, \mathrm{IC} 95 \% \mathrm{Cl} 0, .09-3, .77$ ) com o teste de fluência verbal (FAS), e entre o TUG ( $b=-0,62$, SE = 0,.24, IC 95\%Cl -1,.11--0,14) e a nomeação de animais. CONCLUSÃO: Em idosos da comunidade, níveis elevados de força muscular, equilíbrio dinâmico e aptidão cardiorrespiratória foram positivamente relacionados à cognição global e medidas de função executiva.

PALAVRAS-CHAVE: envelhecimento; cognição; disfunção cognitiva; desempenho físico funcional.

\section{INTRODUCTION}

Physical and cognitive declines often co-exist during the aging process. ${ }^{1}$ Physical changes include physiological alterations leading to muscle mass wasting, with declines in force production ability ${ }^{2}$ and other neuromuscular consequences, eg, neuromuscular junction impairments. ${ }^{3}$ Cognitive changes include neurobiological alterations such as grey and white matter atrophy in the brain and a reduction in the ability to release neurotransmitters in the synaptic cleft, ${ }^{4}$ leading to a decline in performance in neuropsychological tasks of executive functioning and memory. ${ }^{5}$ These phenotypical alterations in both cognitive and physical domains may increase the likelihood of health-related issues such as neurological disease, physical disability, hospitalizations, and premature death. ${ }^{6}$

Previous studies have described the link between physical and cognitive functioning in older individuals. ${ }^{7,8}$ Most of the literature has used gait-related variables (eg, gait velocity and variability) as predictors of adverse health outcomes. For instance, older adults with impaired gait performance presented poor cognitive scores in measures of global and executive functioning, making them more likely to progress to cognitive impairment and dementia. ${ }^{7,9}$ Physical functioning is an umbrella term that is defined as the ability to execute and complete objectively measured performance-based tasks that assess cardiovascular fitness, muscle strength, flexibility, mobility, and/or balance. ${ }^{10}$ Therefore, examining the relationship between gait measures and cognition could be a limited approach, given that gait-related outcomes do not cover all aspects of physical functioning, including subdomains such as lower extremity muscle strength, balance, and mobility. ${ }^{11}$
In this sense, it is reasonable to explore whether a more comprehensive assessment of this construct is associated with cognition. Understanding this relationship may be useful to identify those individuals at risk of cognitive decline through other indicators beyond gait-based measures and provide personalized, tailored interventions to promote physical and cognitive health in older adults. Thus, the aim of our study was to analyze the link between different measures of physical functioning and cognitive functioning in community-dwelling older adults.

\section{METHODS}

Study design, participants, and inclusion criteria

In this cross-sectional study, we included 116 participants recruited from two separate randomized controlled trials (RCT) that examined the effects of resistance training in community-dwelling older adults. ${ }^{12,13}$ We used the baseline data from each study, collected from January to August 2018. All participants provided written informed consent before baseline assessments and received no financial compensation. Reporting of the study is in accordance with the Strengthening the Reporting of Observational studies in Epidemiology (STROBE) guidelines. ${ }^{14}$

Details on the specific eligibility criteria can be found elsewhere. ${ }^{12,13}$ In the present cross-sectional study, participants were included if they met the following criteria: aged 60 or older; absence of clinical conditions or chronic diseases that contraindicate supervised exercise; no previously diagnosed cerebrovascular/cardiac, neurological, or psychiatric conditions (self-reported or in medical records); and having 
sufficient visual and hearing capacity to perform cognitive assessments.

\section{Descriptive variables}

We obtained the general characteristics of participants (including age, sex, and education level) through a questionnaire. Additionally, we measured anthropometric parameters including weight in $\mathrm{kg}$ and height in meters, to compute the body mass index (in $\mathrm{kg} / \mathrm{m}^{2}$ ) of each participant.

\section{Dependent variables: cognitive function}

Global cognitive function was assessed using the Brazilian version of the MoCA. ${ }^{15}$ The MoCA has been widely used as a cognitive screening tool for mild cognitive impairment (MCI). We computed the total MoCA score through the sum of each cognitive domain including visuospatial ability, attention, language, delayed recall, and orientation tasks, with total scores ranging from 0 to 30 , and higher values indicating better performance.

Executive function was obtained through digit span (DS $)^{16}$ and verbal fluency measures. ${ }^{17}$ Forward and backward DS are generated sequences of random numbers gradually increasing to a maximum of nine digits. In Forward DS, the participants repeat the digit sequence in the same order, whereas in Backward DS, the sequences must be repeated in reverse order. The final score was based on the number of successful sequences, with higher scores indicating better performance. In the current study, we computed overall performance as Forward DS minus Backward DS (lower scores indicate better performance).

Regarding verbal fluency measures, participants were requested to say as many words as possible starting with the letters F, A, and S (semantic category) and name animals (phonological category) in one minute. For the semantic category, we computed the sum of words starting with F, $A$, and S (FAS). Higher numbers of evoked words in both categories indicated better performance. All the evaluations were carried out by trained evaluators.

\section{Independent variables: physical functioning}

The physical function variables included were self-paced 4-meter gait speed, five times sit-to-stand, short physical performance battery (SPPB), ${ }^{6}$ timed up and go (TUG) ${ }^{18}$ 6-minute walk test (6MWT), ${ }^{19}$ and lower extremity muscle strength. ${ }^{13}$ Again, all evaluations were performed by trained evaluators.

Performance in the 4-meter usual gait speed and fivetimes sit-to stand test was recorded using a stopwatch. The gait speed test $(\mathrm{m} / \mathrm{s})$ was calculated from the best trial (two attempts) in which participants walked at their usual pace along a 4-meter path. In the five-times sit-to-stand test, we assessed the best time taken by each participant to repeat five consecutive chair rises as quickly as possible. Both measures were extracted from the corresponding SPPB subtests. The $\mathrm{SPPB}^{6}$ is a widely accepted geriatric battery that measures the balance, gait, and strength/endurance of lower limbs from five subtests. The total score was obtained by the sum of the scores, ranging from 0 (poor mobility) to 12 (best mobility).

The TUG measures the time the participant needs to get up from a chair, walk 3 meters towards a line, circle around it (180 degrees), return, and sit back on the chair. ${ }^{18} \mathrm{~A}$ shorter time to completion indicates better performance.

In the $6 \mathrm{MWT},{ }^{19}$ a corridor-based physical function evaluation, the participants were encouraged to walk as far as possible in 6 minutes. At the end of 6 minutes, the maximal walking distance, in meters, was recorded. This outcome has been widely used in clinical trials as a global cardiovascular fitness measure.

Lower extremity muscle strength was assessed using a maximal repetition test (1-RM) in knee extension ${ }^{13}$ and leg press ${ }^{12}$ exercises. A trained evaluator carried out the assessments using previously described consistent and standardized recommendations. ${ }^{20}$ Considering that we used different exercise tests to measure muscle strength of the lower extremities of participants, we computed $z$-scores from leg extension and leg press exercises in order to harmonize this outcome.

\section{Statistical analysis}

All statistical procedures were performed in STATA software, version 13 (StataCorp LLC, College Station, Texas, USA). The level of significance adopted was 5\%. First, exploratory analyses were performed to check the distribution of dependent and independent variables. The participants' characteristics are described using mean and standard deviation or relative frequency (as appropriate).

To analyze the associations between each physical function outcome and cognitive function measures, we performed separate crude and adjusted linear regression analysis, where the covariates included age, sex, educational level, and RCT. Unstandardized coefficients (standard error), 95\% confidence intervals $(95 \% \mathrm{CI})$, and coefficient of determination are presented for the regression models. Additionally, for each regression model, we computed collinearity statistics and conducted residuals analysis to ensure that the assumptions of linear regression were met. In all models, multicollinearity was not an issue among predictor variables, and the residuals were normally distributed and homoscedastic. 


\section{RESULTS}

A flow diagram of the study is presented in Figure 1.

Initially, we screened 262 community-dwelling older adults $(\mathrm{RCT} 1=95 ; \mathrm{RCT} 2=167)$, of which 116 completed the baseline assessment. The main reasons for exclusion of participants from the present analysis were that they did not meet the inclusion criteria $(n=129)$ and could not make the necessary time commitment $(\mathrm{n}=5)$.

Baseline characteristics of all participants and stratified by RCT are shown in Table 1 . The sample was predominantly composed of women (roughly 70\%), the mean age was 69 years, and the mean BMI was $27.37 \mathrm{~kg} / \mathrm{m}^{2}$ (overweight). The mean MoCA score was 20 points, demonstrating signs of probable cognitive impairment, while the mean SPPB was 10 points, which denotes relatively preserved mobility. Altogether, these characteristics reflected phenotypes commonly observed in this subgroup of older individuals.

Table 2 presents the results of the linear regression analysis of the association between physical function and cognition. The crude analysis between physical function measures and global cognitive function showed positive and significant relationships of five-times sit-to-stand, SPPB, 6MWT, and muscle strength performance with MoCA scores. However, after controlling for age, sex, education level, and RCT, only the association between muscle strength and MoCA remained significant $(\mathrm{P}<0.05)$, suggesting that higher levels of lower-extremity muscle strength are related to better scores on global cognitive function.

The crude analysis showed significant associations of gait speed and SPPB with working memory (Forward-Backward DS). However, after controlling for covariates, the statistical significance of these associations disappeared. Additionally, we observed a significant association of all measures of physical function with verbal fluency. After controlling for covariates, the associations of five-times-sit-to-stand, TUG, 6MWT, and lower-extremity muscle strength performance with FAS verbal fluency and between TUG and verbal fluency (animal naming) remained statistically significant $(\mathrm{P}<0.05)$, which suggests that better physical performance (shorter time to complete TUG, higher distances achieved in 6MWT, and greater lower-extremity muscle strength) are associated with better executive function.

\section{DISCUSSION}

We examined the relationship between different measures of physical function and cognition among community-dwelling

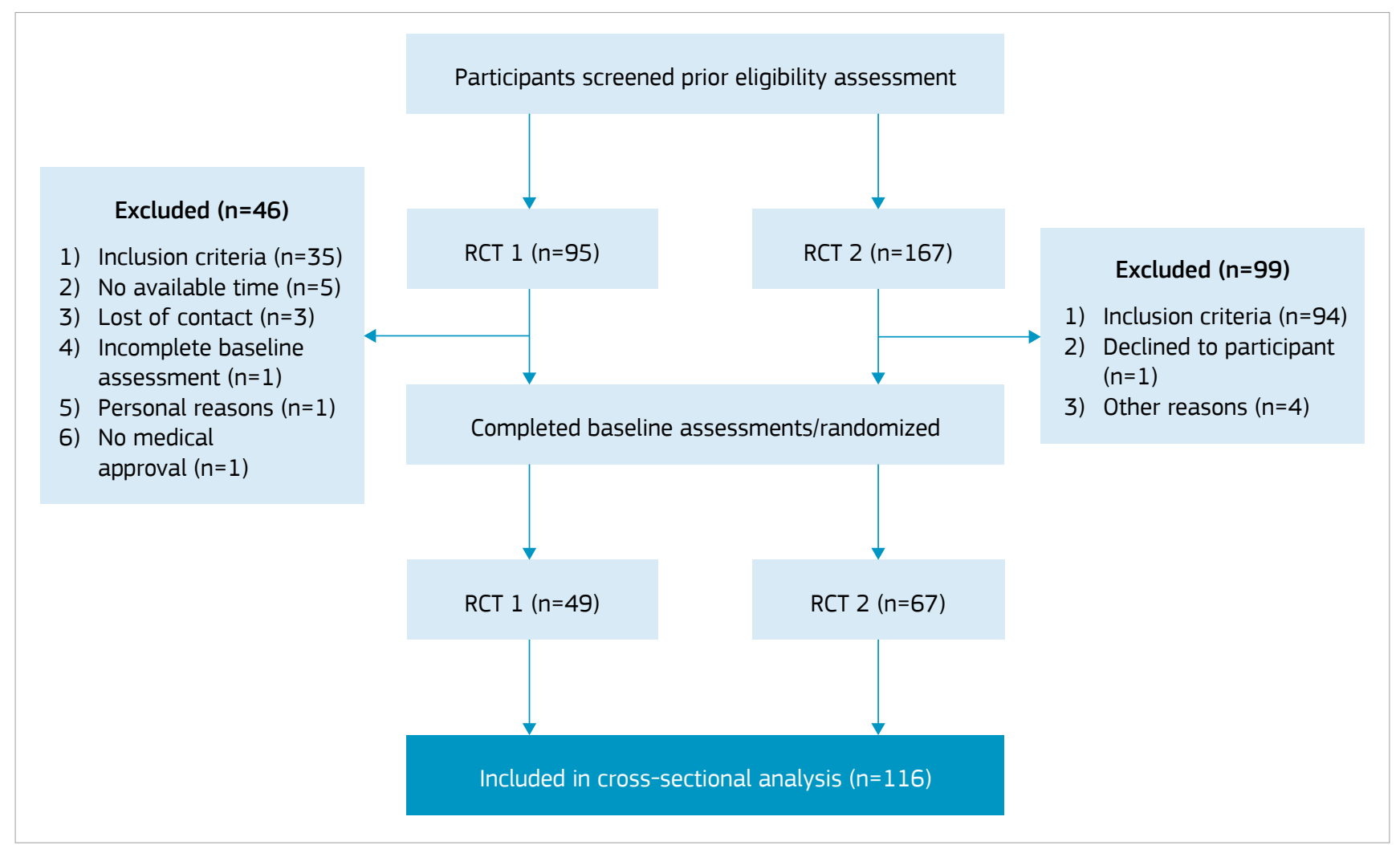

Figure 1. STROBE flowchart. 


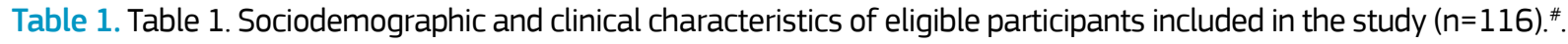

\begin{tabular}{|c|c|c|c|}
\hline Variables & All $(n=116)$ & RCT $1(n=49)$ & RCT $2(n=67)$ \\
\hline Sex (\% female) & 71 & 62 & 78 \\
\hline Age (years) & $69 \pm 6$ & $67 \pm 6$ & $71 \pm 5$ \\
\hline Body mass index $\left(\mathrm{kg} / \mathrm{m}^{2}\right)$ & $27.37 \pm 4.89$ & $26.39 \pm 4.65$ & $28.12 \pm 4.98$ \\
\hline \multicolumn{4}{|l|}{ Educational level (\%) } \\
\hline Low & 45 & 45 & 44 \\
\hline High & 55 & 55 & 55 \\
\hline \multicolumn{4}{|l|}{ Cognitive function } \\
\hline MoCA (score up to 30) & $20 \pm 5$ & $21 \pm 4$ & $19 \pm 4$ \\
\hline Forward minus backward & $1.95 \pm 2.24$ & $1.76 \pm 2.09$ & $2.09 \pm 2.37$ \\
\hline VF (FAS) & $29 \pm 10$ & $31 \pm 10$ & $28 \pm 10$ \\
\hline VF (animal naming) & $13 \pm 4$ & $13 \pm 5$ & $13 \pm 4$ \\
\hline \multicolumn{4}{|l|}{ Physical function } \\
\hline Gait speed (m/s) & $1.01 \pm 0.18$ & $1.04 \pm 0.18$ & $0.99 \pm 0.18$ \\
\hline Sit-to-stand (seconds) & $14.36 \pm 4.51$ & $11.19 \pm 2.87$ & $16.77 \pm 4.01$ \\
\hline SPPB (score 0-12) & $10 \pm 2$ & $11 \pm 1$ & $9 \pm 2$ \\
\hline Timed up and go (sec) & $9.70 \pm 1.73$ & $10.08 \pm 1.63$ & $9.41 \pm 1.76$ \\
\hline 6MWT (meters) & $438 \pm 67$ & $442 \pm 63$ & $435 \pm 70$ \\
\hline Muscle strength (kg) & - & $66 \pm 26^{*}$ & $60 \pm 23^{* *}$ \\
\hline
\end{tabular}

"Data are presented as mean \pm standard deviation (numerical variables) or relative frequency (categorical variables). RCT: Randomized controlled trial; VF: Verbal fluency; *leg extension exercise; ${ }^{* *}$ leg press exercise.

older adults. Our key results demonstrated a positive association between lower-extremity muscle strength and global and executive functioning; there was a significant association between the five-times sit-to-stand, TUG, and 6MWT tests with executive functioning, but we did not demonstrate any association of gait speed or SPPB performance with cognitive outcomes.

Our study observed significant associations between lower-extremity muscle strength and global cognition and executive function, which are consistent with observational studies. For instance, Boyle et al. ${ }^{21}$ showed that muscle strength was independently associated with cognitive decline (mean follow-up $=3.60$ years). A systematic review ${ }^{1}$ also demonstrated that there was a positive correlation between the size of the exercise-induced effect on physical function and on cognitive function. Moreover, in a secondary analysis from the SMART study, Mavros et al..$^{22}$ showed that the cognitive improvements after a progressive resistance training program were mediated by lower-extremity muscle strength gains.

The relationship between muscle strength and cognitive function is still unclear. A neuroimaging study ${ }^{23}$ suggested that white-matter integrity may be a candidate, given that these structures play a role in the central nervous system to trigger motor drive outputs and promote muscle contraction, but also during performance of executive function-related tasks. Other potential mechanisms include changes in phenotypes related to muscle weakness and cognitive impairment during aging, such as low-grade inflammation and mitochondrial dysregulation. ${ }^{24}$

Another key finding was a significant association of the five-times sit-to-stand, TUG, and 6MWT tests with verbal fluency. Although the literature has reported associations between global cognitive function and the five-times sit-tostand test, ${ }^{25}$ another study ${ }^{26}$ observed that the association between motor performance was consistently greater for the executive function test than the global cognitive function in a sample of 3,075 participants, which is partially in line with our results.

Performing the TUG task requires synchronization of transfers, turning, and walking, which involves activation of brain regions related to executive functioning in order to promote planning and execution of a goal-directed action. In fact, previous work by Donoghue et al. ${ }^{27}(\mathrm{n}=4,998)$ 
Table 2. Results of crude and adjusted separate linear regression models of the association of physical function with each cognitive outcome.

\begin{tabular}{|c|c|c|c|c|c|}
\hline \multirow[b]{2}{*}{ Independent variables } & \multirow{2}{*}{$\begin{array}{l}\text { Adjusted } \\
\mathbf{R}^{2}\end{array}$} & \multicolumn{2}{|c|}{ Crude analysis } & \multicolumn{2}{|c|}{ Adjusted analysis* } \\
\hline & & $\begin{array}{l}\text { Unstandardized b } \\
\text { (standard error) }\end{array}$ & $95 \% \mathrm{Cl}$ & $\begin{array}{l}\text { Unstandardized b } \\
\text { (standard error) }\end{array}$ & $95 \% \mathrm{Cl}$ \\
\hline \multicolumn{6}{|l|}{ MoCA (score up to 30) } \\
\hline Gait speed $(\mathrm{m} / \mathrm{s})^{\mathrm{a}}$ & 0.10 & $4.41(2.28)$ & $-0.10-8.93$ & $1.34(2.43)$ & $-3.47-6.16$ \\
\hline Five-times sit-to-stand (sec) ${ }^{a}$ & 0.11 & $-0.28(0.09)$ & $-0.45-0.10$ & $-0.17(0.12)$ & $-0.40-0.06$ \\
\hline SPPB (score 0-12) ${ }^{c}$ & 0.09 & $0.64(0.25)$ & $0.13-1.15$ & $0.28(0.31)$ & $-0.34-0.91$ \\
\hline Timed up and go (sec) ${ }^{\mathrm{b}}$ & 0.11 & $-0.38(0.24)$ & $-0.86-0.11$ & $-0.31(0.25)$ & $-0.82-0.19$ \\
\hline 6MWT (meters) ${ }^{\mathrm{b}}$ & 0.11 & $0.01(0.01)$ & $0.00-0.03$ & $0.01(0.01)$ & $-0.01-0.02$ \\
\hline Muscle strength (z-score) ${ }^{c}$ & 0.16 & $0.85(0.43)$ & $0.01-1.70$ & $0.84(0.40)$ & $0.05-1.64$ \\
\hline \multicolumn{6}{|l|}{ Forward minus backward } \\
\hline Gait speed $(\mathrm{m} / \mathrm{s})^{a}$ & 0.04 & $-2.41(1.13)$ & $-4.67--0.16$ & $-1.44(1.27)$ & $-3.98-1.09$ \\
\hline Five-times sit-to-stand (sec) ${ }^{a}$ & 0.05 & $0.09(0.05)$ & $-0.01-0.18$ & $0.07(0.06)$ & $-0.05-0.20$ \\
\hline SPPB (score 0-12) ${ }^{c}$ & 0.06 & $-0.27(0.13)$ & $-0.54--0.01$ & $0.20(0.16)$ & $-0.53-0.12$ \\
\hline Timed up and go (sec) ${ }^{\mathrm{b}}$ & 0.04 & $0.22(0.12)$ & $-0.02-0.46$ & $0.19(0.13)$ & $-0.07-0.45$ \\
\hline 6MWT (meters) ${ }^{\mathrm{b}}$ & 0.03 & $-0.00(0.00)$ & $-0.01-0.00$ & $-0.00(0.01)$ & $-0.01-0.01$ \\
\hline Muscle strength (z-score) ${ }^{c}$ & 0.02 & $-0.10(0.21)$ & $-0.52-0.33$ & $-0.10(0.22)$ & $-0.51-0.35$ \\
\hline \multicolumn{6}{|l|}{ Verbal fluency (FAS) } \\
\hline Gait speed $(\mathrm{m} / \mathrm{s})^{\mathrm{a}}$ & 0.17 & $15.28(5.10)$ & $5.16-25.40$ & $9.27(5.45)$ & $-1.53-20.09$ \\
\hline Five-times sit-to-stand (sec) a & 0.19 & $-0.71(0.21)$ & $-1.11-0.30$ & $-0.63(0.26)$ & $-1.15--0.12$ \\
\hline SPPB (score 0-12) ${ }^{c}$ & 0.18 & $1.70(0.59)$ & $0.51-2.89$ & $1.22(0.70)$ & $-0.16-2.62$ \\
\hline Timed up and go (sec) ${ }^{\mathrm{b}}$ & 0.18 & $-1.43(0.55)$ & $-2.52--0.35$ & $-1.13(0.57)$ & $-2.26--0.01$ \\
\hline 6MWT (meters) ${ }^{\mathrm{b}}$ & 0.20 & $0.04(0.01)$ & $0.01-0.07$ & $0.04(0.02)$ & $0.01-0.07$ \\
\hline Muscle strength (z-score) ${ }^{c}$ & 0.18 & $2.00(0.98)$ & $0.07-3.93$ & $1.92(0.93)$ & $0.09-3.77$ \\
\hline \multicolumn{6}{|l|}{ Verbal fluency (animal naming) } \\
\hline Gait speed (m/s) a & 0.10 & $6.44(2.13)$ & $2.22-10.66$ & $4.30(2.36)$ & $-0.38-9.00$ \\
\hline Five-times sit-to-stand (sec)a & 0.09 & $-0.18(0.09)$ & $-0.36--0.01$ & $-0.16(0.12)$ & $-0.38-0.07$ \\
\hline SPPB (score 0-12) c & 0.10 & $0.53(0.25)$ & $0.03-1.03$ & $0.43(0.30)$ & $-0.17-1.04$ \\
\hline Timed up and go (sec) $)^{\mathrm{b}}$ & 0.13 & $-0.77(0.22)$ & $-1.21--0.32$ & $-0.62(0.24)$ & $-1.11--0.14$ \\
\hline 6MWT (meters) ${ }^{\mathrm{b}}$ & 0.08 & $0.01(0.01)$ & $-0.00-0.02$ & $0.01(0.01)$ & $-0.01-0.02$ \\
\hline Muscle strength (z-score)c & 0.08 & $0.54(0.41)$ & $-0.28-1.37$ & $0.39(0.41)$ & $-0.43-1.22$ \\
\hline
\end{tabular}

${ }^{*}$ Adjusted by age, sex, education, and RCT; Bold denotes $p<0.05$. Participants included in each analysis: ${ }^{a} n=115 ;{ }^{b} n=114 ;{ }^{c} n=110$.

demonstrated an independent association between the TUG and several measures of cognitive performance, including letter fluency, in adults aged 50 and older. Moreover, we found a significant association between walking capacity and cognitive function. Baldasseroni et al..$^{28}$ demonstrated a similar association between global cardiorespiratory fitness, measured by the $6 \mathrm{MWT}$, and cognitive function in patients with heart failure.
A reasonable explanation may be attributed to impaired executive functions, visuospatial skills, and processing speed, which may be critical aspects of the lack of ability to plan and execute lower-extremity tasks. ${ }^{29}$ Contributing to this hypothesis, a neuroimaging study observed that physical function decline is associated with age-related white-matter alterations. ${ }^{30}$ Additionally, the association of cognitive performance with cardiorespiratory function may be explained 
by positive adaptations in cerebral vascularization. In fact, high aerobic fitness is related to mechanisms such as better cerebral blood flow and greater production of neurotrophic factors, aspects that are related to better cognitive performance. ${ }^{31}$

Curiously, we did not find a significant association between gait speed and cognition. However, this finding should be considered with caution. For example, in the Health, Aging, and Body Composition Study - a prospective cohort that examined 2,876 older adults, all initially well-functioning, over a nine-year period - Best et al. ${ }^{7}$ demonstrated that gait speed decline was a precursor of cognitive decline. Additionaly, Montero-Odasso et al. ${ }^{8}$ analyzed the trajectories of physical and cognitive decline in 154 older adults free of dementia at baseline, and their results indicated that serial measures of gait speed have a higher attributable risk for incident dementia. Moreover, the authors highlighted that applying a single gait assessment at baseline was not sufficient to identify individuals at a high risk of cognitive decline, since motor decline was not uniform or linear. This may explain the absence of significance in the association between cognitive measures and gait speed in the present study.

In the present study, the SPPB was not associated with cognitive function. The literature related to these measures is not conclusive. ${ }^{32,33}$ For example, in a cross-sectional study with 114 older adults, the authors did not observe significant associations between SPPB and global cognitive function. ${ }^{32}$ On the other hand, Moon et al., ${ }^{33}$ in a 5-year follow-up study with 297 participants, observed that the decline in physical function assessed by the SPPB was independently associated with risk of later cognitive impairment in older adults. Despite these inconsistencies, the SPPB is a highly relevant measure in routine geriatric care and is related to activities of daily living, disability, hospitalization, and death. ${ }^{6}$

Our findings have important practical implications. Inexpensive, quick, simple, and reliable measures of physical function could be incorporated into geriatric assessment routines to monitor and even screen for physical and cognitive performance among older adults.

The limitations of this study must also be taken into account:

- The cross-sectional design does not allow establishment of a causal relationship;

- Performing secondary analysis from separate studies is a common strategy used to explore research questions. However, this approach may significantly impair external validity. To minimize the likelihood of bias from sources, we performed regression models which included each RCT study as a covariate in the multiple analysis. Additionally, we highlighted that the participants of each RCT had relatively the same characteristic, the elegibility criteria between studies were not substantially different, and we used similar methodology to assess each outcome of interest. Therefore, further study is necessary to confirm and reproduce our findings;

- Our sample was small compared with previous studies and included older adults living independently in the community, with relatively preserved physical and cognitive functioning. Thus, our findings should be interpreted with caution among participants with other clinical characteristics (eg, frail individuals);

- The low education levels of the participants may have influenced the performance of global and executive functioning tasks;

- Our sample size limited exploration of moderating factors, including sex; and

- We did not measure neurobiological markers to explore underlying mechanisms.

\section{CONCLUSION}

In community-dwelling older adults, higher levels of muscle strength, dynamic balance, and cardiorespiratory fitness were positively associated with global cognition and executive control measures. Prescribing exercise interventions (eg, resistance training) at the individual and community level, with a focus on improving physical functioning domains such as muscle strength, postural balance, and cardiorespiratory capacity, may help promote cognitive health in older people. Our findings also suggest that including a comprehensive assessment that covers more domains of physical function beyond gait-related parameters may be a promising strategy to identify individuals at risk of cognitive decline. Future studies are necessary to clarify this research gap.

\section{CONFLICT OF INTEREST}

The authors declared no conflicts of interest.

\section{FUNDING}

This research did not receive any specific grant from funding agencies in the public, commercial, or not-forprofit sectors. 


\section{AUTHORS' CONTRIBUTION}

JFNA: formal analysis, writing - original draft, writing - review \& editing. BRC: conceptualization, data curation, formal analysis, writing - original draft, writing - review \& editing. AAV: writing - review \& editing. IRC: writing
- review \& editing. MLLT: writing - review \& editing. RCA: conceptualization, data curation, supervision, writing - original draft, writing - review \& editing. MFS: data curation, formal analysis, supervision, writing - original draft, writing - review \& editing.

\section{REFERENCES}

1. Falck RS, Davis JC, Best JR, Crockett RA, Liu-Ambrose T. Impact of exercise training on physical and cognitive function among older adults: a systematic review and meta-analysis. Neurobiol Aging. 2019;79:119-30. https://doi.org/10.1016/j. neurobiolaging.2019.03.007

2. Cruz-Jentoft AJ, Sayer AA. Sarcopenia. Lancet. 2019;393(10191):263646. https://doi.org/10.1016/s0140-6736(19)31138-9

3. Gonzalez-Freire M, de Cabo R, Studenski SA, Ferrucci L. The Neuromuscular Junction: Aging at the Crossroad between Nerves and Muscle. Front Aging Neurosci. 2014;6:208. https://doi.org/10.3389/ fnagi.2014.00208

4. Barha CK, Nagamatsu LS, Liu-Ambrose T. Basics of neuroanatomy and neurophysiology. Handb Clin Neurol. 2016;138:53-68. https:// doi.org/10.1016/b978-0-12-802973-2.00004-5

5. Salthouse TA. When does age-related cognitive decline begin? Neurobiol Aging. 2009;30(4):507-14. https://doi.org/10.1016/j. neurobiolaging.2008.09.023

6. Guralnik JM, Simonsick EM, Ferrucci L, Glynn RJ, Berkman LF, Blazer DG, et al. A short physical performance battery assessing lower extremity function: association with self-reported disability and prediction of mortality and nursing home admission. J Gerontol. 1994;49(2):M85-94. https://doi.org/10.1093/geronj/49.2.m85

7. Best JR, Liu-Ambrose T, Boudreau RM, Ayonayon HN, Satterfield S, Simonsick EM, et al. An Evaluation of the Longitudinal, Bidirectional Associations Between Gait Speed and Cognition in Older Women and Men. J Gerontol A Biol Sci Med Sci. 2016;71(12):1616-23. https://doi.org/10.1093/gerona/glw066

8. Montero-Odasso M, Speechley M, Muir-Hunter SW, Sarquis-Adamson Y, Sposato LA, Hachinski V, et al. Motor and Cognitive Trajectories Before Dementia: Results from Gait and Brain Study. J Am Geriatr Soc. 2018;66(9):1676-83. https://doi.org/10.1111/jgs.15341

9. Verghese J, Lipton RB, Hall CB, Kuslansky G, Katz MJ, Buschke H. Abnormality of Gait as a Predictor of Non-Alzheimer's Dementia. N Engl J Med. 2002;347(22):1761-8. https://doi.org/10.1056/ nejmoa020441

10. Painter P, Stewart AL, Carey S. Physical functioning: definitions, measurement, and expectations. Adv Ren Replace Ther. 1999;6(2): 11023. https://doi.org/10.1016/s1073-4449(99)70028-2

11. Kueper JK, Speechley M, Lingum NR, Montero-Odasso M. Motor function and incident dementia: a systematic review and metaanalysis. Age Ageing. 2017;46(5):729-38. https://doi.org/10.1093/ ageing/afx084

12. Cavalcante BR, de Souza MF, Falck RS, Liu-Ambrose T, Behm DG, Pitangui ACR, et al. Effects of Resistance Exercise with Instability on Cognitive Function (REI Study): A Proof-Of-Concept Randomized Controlled Trial in Older Adults with Cognitive Complaints. J Alzheimers Dis. 2020;77(1):227-39. https://doi.org/10.3233/jad-200349

13. Santos PRP, Cavalcante BR, Vieira AKDS, Guimarães MD, Leandro da Silva AM, Armstrong ADC, et al. Improving cognitive and physical function through 12-weeks of resistance training in older adults: Randomized controlled trial. J Sports Sci. 2020;38(17):1936-42. https://doi.org/10.1080/02640414.2020.1763740

14. Elm E von, Altman DG, Egger M, Pocock SJ, Gøtzsche PC, Vandenbroucke JP. Strengthening the reporting of observational studies in epidemiology (STROBE) statement: guidelines for reporting observational studies. BMJ. 2007;335:806-8. https:// doi.org/10.1136/bmj.39335.541782.AD
15. Memória CM, Yassuda MS, Nakano EY, Forlenza OV. Brief screening for mild cognitive impairment: validation of the Brazilian version of the Montreal cognitive assessment. Int J Geriatr Psychiatry. 2013;28(1):34-40. https://doi.org/10.1002/gps.3787

16. Wechsler D. WAIS-R manual: Wechsler adult intelligence scalerevised. Psychological Corporation; 1981.

17. Whiteside DM, Kealey T, Semla M, Luu H, Rice L, Basso MR, et al Verbal Fluency: Language or Executive Function Measure? Appl Neuropsychol Adult. 2016;23(1):29-34. https://doi.org/10.1080/2 3279095.2015.1004574

18. Shumway-Cook A, Brauer S, Woollacott M. Predicting the Probability for Falls in Community-Dwelling Older Adults Using the Timed Up $\%$ Go Test. Phys Ther. 2000;80(9):896-903.

19. Harada ND, Chiu V, Stewart AL. Mobility-related function in older adults: assessment with a 6-minute walk test. Arch Phys Med Rehabil. 1999;80(7):837-41. https://doi.org/10.1016/s0003-9993(99)90236-8

20. Nascimento MA, Januário B, Gerage AM, Mayhew JL, Pina FLC, Cyrino ES. Familiarization and Reliability of One Repetition Maximum Strength Testing in Older Women. J Strength Cond Res. 2013;27(6):1636-42. https://doi.org/10.1519/jsc.0b013e3182717318

21. Boyle PA, Buchman AS, Wilson RS, Leurgans SE, Bennett DA. Association of Muscle Strength With the Risk of Alzheimer Disease and the Rate of Cognitive Decline in Community-Dwelling Older Persons. Arch Neurol. 2009;66(11):1339-44. https://doi.org/10.1001/ archneurol.2009.240

22. Mavros Y, Gates N, Wilson GC, Jain N, Meiklejohn J, Brodaty $\mathrm{H}$, et al. Mediation of Cognitive Function Improvements by Strength Gains After Resistance Training in Older Adults with Mild Cognitive Impairment: Outcomes of the Study of Mental and Resistance Training. J Am Geriatr Soc. 2017;65(3):550-9. https:// doi.org/10.1111/jgs.14542

23. Moon SY, Souto Barreto P, Rolland Y, Chupin M, Bouyahia A, Fillon L, et al. Prospective associations between white matter hyperintensities and lower extremity function. Neurology. 2018;90(15):e1291-e1297. https://doi.org/10.1212/wnl.0000000000005289

24. Chhetri JK, Barreto PS, Fougère B, Rolland Y, Vellas B, Cesari M. Chronic inflammation and sarcopenia: A regenerative cell therapy perspective. Exp Gerontol. 2018;103:115-23. https://doi.org/10.1016/j. exger.2017.12.023

25. Annweiler C, Schott A-M, Abellan Van Kan G, Rolland Y, Blain H, Fantino B, et al. The Five-Times-Sit-to-stand test, a marker of global cognitive functioning among community-dwelling older women. J Nutr Health Aging. 2011;15(4):271-6. https://doi.org/10.1007/ s12603-011-0037-1

26. Rosano C, Simonsick EM, Harris TB, Kritchevsky SB, Brach J, Visser $\mathrm{M}$, et al. Association between physical and cognitive function in healthy elderly: the health, aging and body composition study. Neuroepidemiology. 2005;24(1-2):8-14. https://doi. org/10.1159/000081043

27. Donoghue OA, Horgan NF, Savva GM, Cronin H, O'Regan C, Kenny RA. Association between timed up-and-go and memory, executive function, and processing speed. J Am Geriatr Soc. 2012;60(9):1681-6. https://doi.org/10.1111/j.1532-5415.2012.04120.x

28. Baldasseroni S, Mossello E, Romboli B, Orso F, Colombi C, Fumagalli S, et al. Relationship between cognitive function and 6-minute walking test in older outpatients with chronic heart failure. Aging Clin Exp Res. 2010;22(4):308-13. https://doi.org/10.1007/bf03324936 
29. Coppin AK, Shumway-Cook A, Saczynski JS, Patel KV, Ble A, Ferrucci $L$, et al. Association of executive function and performance of dualtask physical tests among older adults: analyses from the InChianti study. Age Ageing. 2006;35(6):619-24. https://doi.org/10.1093/ ageing/afl107

30. He L, de Souto Barreto P Giudici KV Gabelle A, Perus L, Mangin J-F, et al. Five-Year Lower Extremity Function is Associated with White Matter Abnormality in Older Adults. J Am Geriatr Soc. 2021;69(4):9951002. https://doi.org/10.1111/jgs.16989

31. Marmeleira J. An examination of the mechanisms underlying the effects of physical activity on brain and cognition. Eur Rev Aging
Phys Act. 2013;10(2):83-94. https://doi.org/10.1007/s11556-0120105-5

32. Ishihara K, Izawa KP, Kitamura M, Shimogai T, Kanejima $Y$, Morisawa T, et al. Influence of mild cognitive impairment on activities of daily living in patients with cardiovascular disease Heart Vessels. 2019;34(12):1944-51. https://doi.org/10.1007/ s00380-019-01437-7

33. Moon JH, Moon JH, Kim KM, Choi SH, Lim S, Park KS, et al. Sarcopenia as a Predictor of Future Cognitive Impairment in Older Adults. J Nutr Health Aging. 2016;20(5):496-502. https://doi.org/10.1007/ s12603-015-0613-x 